\title{
THERMAL RADIATION BETWEEN THE DRIVER AND THE VEHICLE CABIN INTERIOR
}

\author{
Dragan Ružić ${ }^{1}$, Stjepan Galamboš ${ }^{2}$
}

UDC:629.113;614.8.084

\section{INTRODUCTION}

Air temperature, radiant temperature, humidity and air movement are the four basic environmental variables that affect human response to thermal environments and therefore his thermal sensation. Combined with the metabolic activity and clothing, they provide the six fundamental factors that define human thermal environments. They are used to calculate heat transfer to and from the human body. Actually, a person feels heat exchange not the air temperature or the air velocity. Radiative heat transfer between the human body and the surrounding has the same significance as the convective heat transfer influenced by the air temperature and the air movement. Heat is exchanged by radiation between all bodies, and there is a heat flow from a hot to a cold body depended on the temperature difference between the two bodies and to emissivity of the surfaces.

Cabin of motor vehicle is a special environment due to confined space and possible occurrence of surfaces with high temperature, significantly higher that can be encountered in buildings. Therefore it is very important to include the radiative heat exchange in investigation of thermal conditions inside the vehicle cabin. In the case of cabin of passenger car, the interior thermal environment has significant impact on driver's performance, hence on driving safety. It must be bear in mind that even under moderate outside conditions the closed cabin act like green house and its closed interior could become unpleasant, unbearable and even dangerous [1], [2], [6], [8], [9]. The AC system is not able to directly change mean radiant temperature, except by decreasing the temperature of the inner surfaces, although very slowly.

Experimental determination of local heat fluxes on human body surface demands the use of complex and expensive measurement equipment and test facilities [1], [3], [4], [6], [10]. The other way is to simulate these processes in virtual experiments. This paper focuses on numerical modelling of radiative heat exchange between the driver and passenger car cabin interior, but excluding the effects of the solar radiation transmitted through a cabin glazing.

\section{METHOD}

The simulations were done in CFD software STAR-CCM+. The software includes the Surface-To-Surface Gray Thermal radiation model for simulation of diffuse radiation independently of wavelength with non-participating media. With this model, radiation properties of the media and surrounding surfaces are considered the same for all wavelengths. The air that fills the space between the surfaces does not absorb, emit or scatter radiation.

${ }^{1}$ Dragan Ružić, Ph.D., assist. prof., University of Novi Sad, Faculty of Technical Sciences, Trg Dositeja Obradovića 6, Novi Sad, ruzic@uns.ac.rs

${ }^{2}$ Stjepan Galamboš, MSc. assist., University of Novi Sad, Faculty of Technical Sciences, Trg Dositeja Obradovića 6, Novi Sad 
The surface properties are emissivity, reflectivity, transmissivity and the surface temperature. In this case, for the thermal radiation analysis inside the vehicle cabin, all surfaces are considered as an opaque for the thermal radiation (zero transmissivity) and absorptivity is equal to emissivity (Kirchhoff's law).

\subsection{Theoretical background}

Sensible heat exchange between the driver and the interior of the cabin directly contributes to the thermal sensation and takes place by convection, conduction and thermal radiation, including the solar radiation passing through glass of a cabin. To make thermal conditions comfortable, a driver is able to directly influence only the heat transfer by forced convection by changing modes of air flow over the surface of his body. This system changes the air temperature in the cabin by mixing ventilation. Indirectly, the temperature of interior surfaces will be changed too, although much more slowly [9].

When surrounded by surfaces with higher temperature than that of their skin and clothing $\left(t_{s k}, t_{c l}\right)$, a person receives the heat by thermal radiation $\left(q_{r}\right)$. Thermal radiation flux from hot surrounding surfaces depends on the wall surface temperature and the emissivity of the wall $(\varepsilon)$. The wall temperature and its emissivity are expressed by mean radiant temperature $\left(t_{m r}\right)$ and linear radiative heat transfer coefficient $\left(h_{r}\right)$ Error! Reference source not found., Error! Reference source not found.:

$q_{r}=h_{r} \cdot f_{c l} \cdot\left(t_{m r}-t_{c l}\right), \mathrm{W} / \mathrm{m}^{2}$

$h_{r}=2.88 \cdot \varepsilon \cdot \sigma\left(273.2+\frac{t_{c l}+t_{m r}}{2}\right)^{3}, \mathrm{~W} / \mathrm{m}^{2} \mathrm{~K}$

The mean radiant temperature is the uniform temperature of an imaginary enclosure in which radiant heat transfer from the human body is equal to the radiant heat transfer in the actual non-uniform enclosure [5]. This parameter has equal significance for heat exchange between the human body and the environment as an air temperature. It depends on surface temperatures, surface shapes and emissivity. The emissivity of nonmetallic surfaces is generally high, 0.9 and higher, just like the emissivity of the human skin and clothing [9].

\subsection{The model}

The interior of the cabin is modelled on the shape and dimensions of middle class passenger hatchback car, with significant simplification of the cabin geometry. The model was made in CAD software CATIA. The interior of the cabin was discretized in about 168,000 finite volumes and about 154,000 surfaces. Fig. 1.

The driver is modelled as a virtual thermal manikin. The virtual thermal manikin was developed on Faculty of Technical Sciences - University of Novi Sad (VTMFTS) [7]. The CAD model of the virtual thermal manikin (VTM) is a simplified humanoid in the sitting posture. Main body dimensions are adopted from CATIA database for a 50th percentile European male. According to the chosen sizes of the body, the VTM is $1.74 \mathrm{~m}$ tall and weighs $68 \mathrm{~kg}$. The area of VTM body surface in sitting position is $1.796 \mathrm{~m}^{2}$. The manikin's body is divided into 18 segments, (head, neck, chest, back, etc.) in order to monitor the heat exchange on individual segments (Fig. 2). A method with constant temperature of the manikin's body surface was used. The driver body surface is divided into about 13,800 surfaces. 


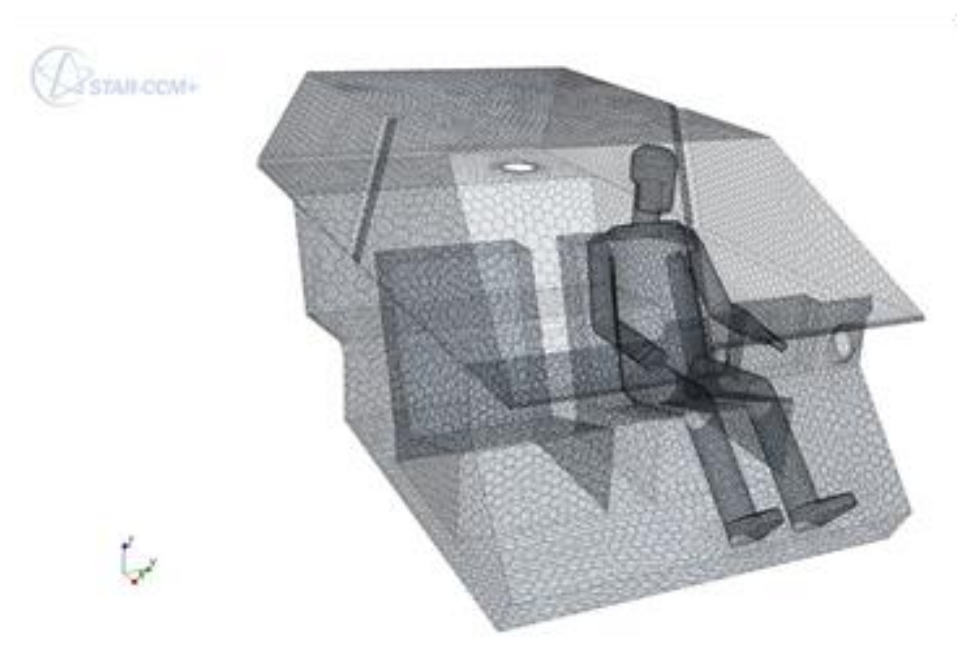

Figure 1 Meshed model of the passenger car cabin with driver

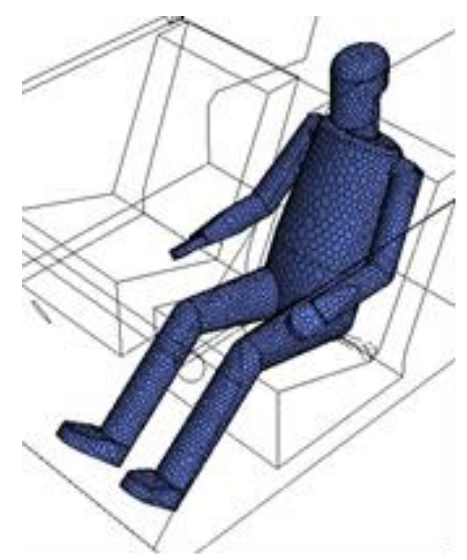

Figure 2 The virtual thermal manikin VTMFTS

\section{BOUNDARY CONDITIONS}

The manikin's surface temperature was $34^{\circ} \mathrm{C}$ for bare skin (head, hands and lower arms) and $30^{\circ} \mathrm{C}$ for the segments covered by clothing. In all virtual experiments only the driver was present.

It was presumed that the emissivity of all interior surfaces as well as of human body is 0.95 . This value is taken as a typical value for materials involved in radiative heat exchange inside vehicle cabin (glass, polymers, clothing and human skin) [9].

Boundary conditions for the virtual experiments are given in Table 1. Moderate conditions are the conditions where the air temperature is $26^{\circ} \mathrm{C}$, while in hot conditions it is assumed that the air temperature is $34^{\circ} \mathrm{C}$. In moderate and hot conditions all surfaces have 
the same temperature, equal to the air temperature. In non-uniform conditions some of the surfaces are on the higher temperature due to solar radiation or heat gain from the powertrain. The surface temperatures are chosen according to boundary conditions proposed by relevant standards combining with empirical data [1], [8], [9], [11], [12], [13].

Table 1 Temperatures of the cabin interior surfaces $\left({ }^{\circ} \mathrm{C}\right)$

\begin{tabular}{|c|c|c|c|c|}
\hline & moderate & $\begin{array}{c}\text { moderate } \\
\text { non-uniform }\end{array}$ & hot & $\begin{array}{c}\text { hot } \\
\text { non-uniform }\end{array}$ \\
\hline windshield & 26 & 34 & 34 & 42 \\
\hline instrument panel & 26 & 34 & 34 & 42 \\
\hline firewall & 26 & 34 & 34 & 42 \\
\hline side window & 26 & 26 & 34 & 34 \\
\hline seat & 26 & 26 & 34 & 34 \\
\hline ceiling & 26 & 34 & 34 & 42 \\
\hline other interior surfaces & 26 & 26 & 34 & 34 \\
\hline
\end{tabular}

\section{RESULTS AND DISCUSSION}

The thermal radiation heat flux on individual segments of the driver's body and mean radiant temperatures are the main results obtained by the simulations post-processing. In Fig. 3 the thermal radiation heat fluxes are graphically presented. The negative values indicate heat gain by the thermal radiation. Values on the line portion between two body segments have no meaning, of course.

It can be noted that even under the uniform conditions the highest heat exchange is on segments that are directly exposed to the surrounding surfaces (head, arms and hands). The non-uniformity of the temperatures of the surrounding surfaces under chosen conditions obviously has less influence than the total heat transfer by thermal radiation. Thermal radiation flux on the driver's body in moderate uniform conditions and in hot non-uniform conditions are shown in fig. 4 and 5, respectively (Note: the sign of the flux is opposite to that in the graph in Fig. 3). Strong thermal radiation on head and lower legs due to high temperature of surrounding surfaces can be noticed on fig. 5 .

Mean radiant temperatures for individual segments of the driver's body are given on graph in Fig. 6. Distributions of mean radiant temperature on the driver's body in moderate uniform and in hot non-uniform conditions can be seen on Fig. 7 and Fig. 8. For the same boundary conditions, the distribution of local mean radiant temperature is more uniform than thermal radiation heat flux. The cause is difference in values of linear radiative heat transfer coefficient between individual body segments (Eq. 2). 


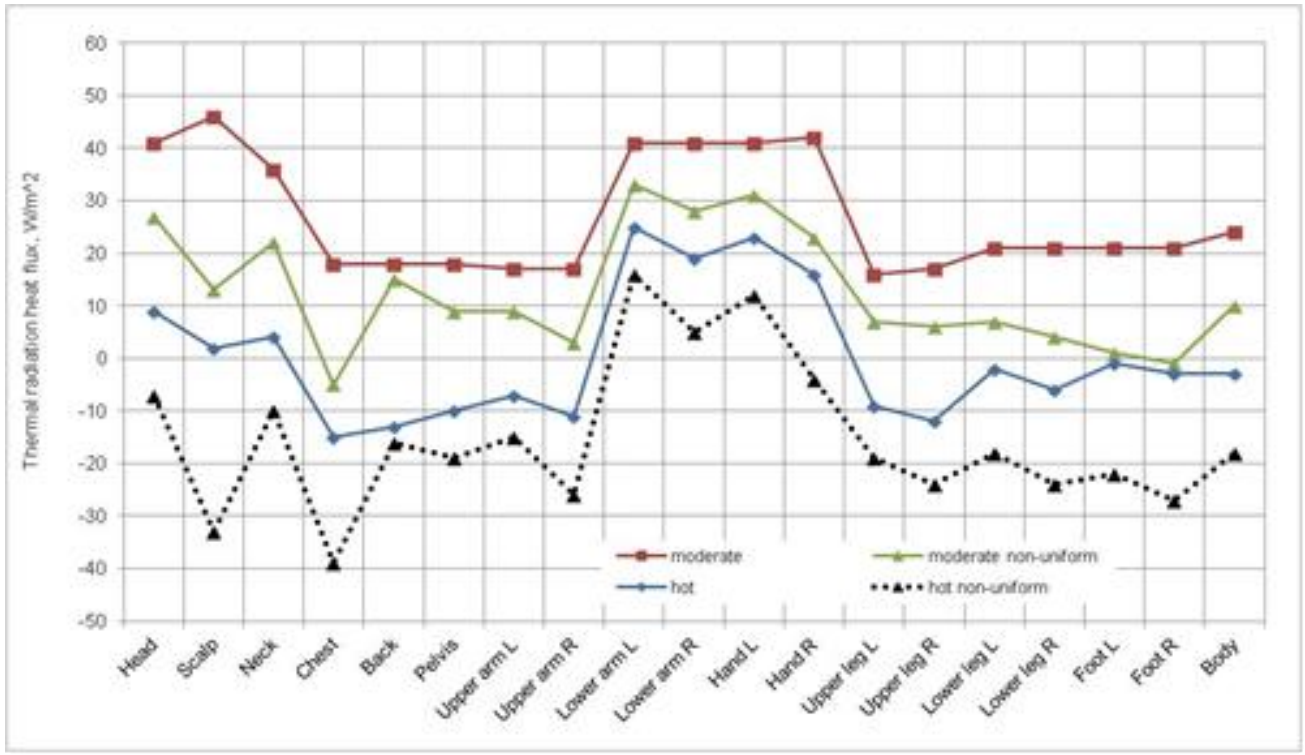

Figure 3 The thermal radiation heat flux on individual segments of the driver's body

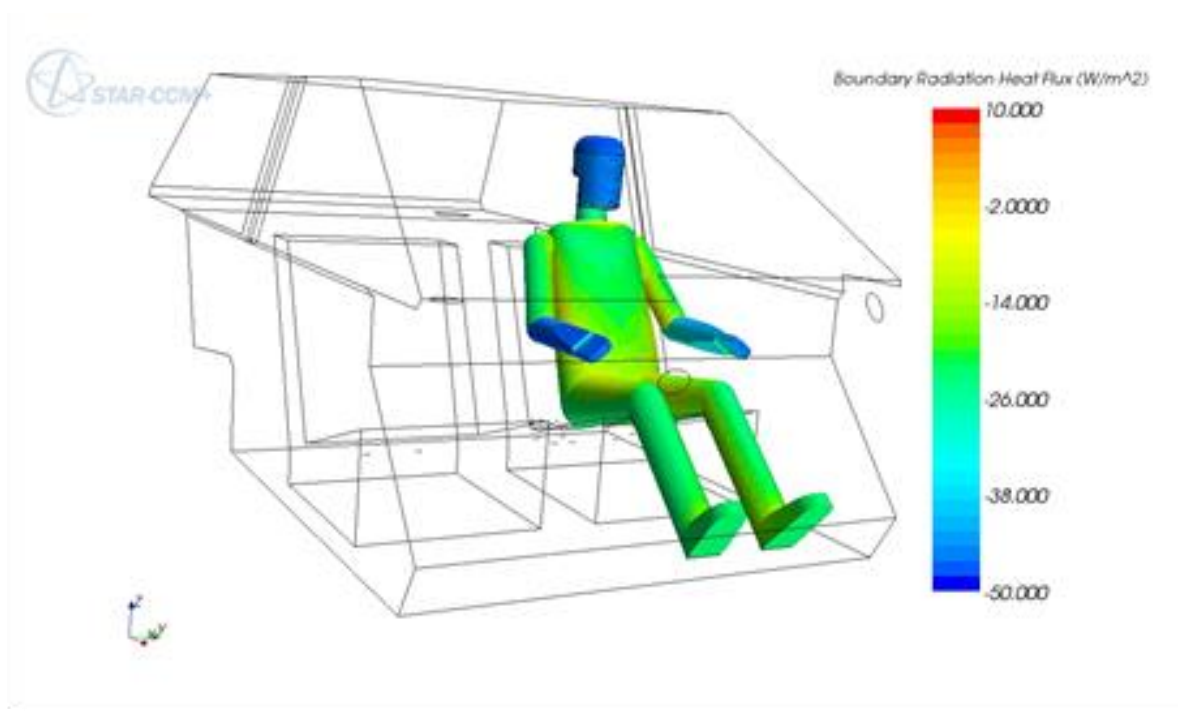

Figure 4 Visualisation of thermal radiation flux on the driver's body in moderate uniform conditions 


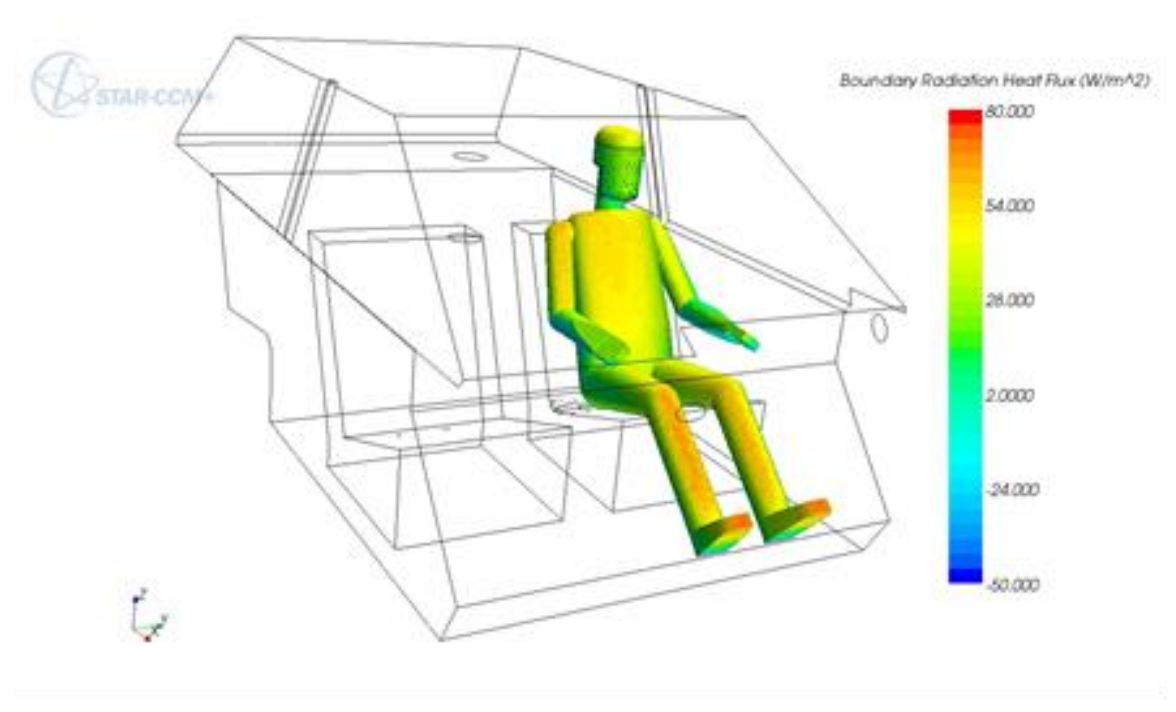

Figure 5 Visualisation of thermal radiation flux on the driver's body in hot non-uniform conditions

The values mainly correspond to the temperature of the surrounding surfaces, due to high value of emissivity. In the experiments performed by Ružić [6] and Agošton [1] under the hot outdoor conditions with solar radiation, the values of mean radiant temperatures that are encountered inside the cabin of passenger car were in the range of 35 to $45^{\circ} \mathrm{C}$.

The relationship between the thermal radiation heat flux and mean radiant temperature is given in Eq. 1. Under the chosen boundary conditions, average values of linear radiative heat transfer coefficient for whole body are in range from 5.1 to $6.6 \mathrm{~W} / \mathrm{m}^{2} \mathrm{~K}$. This value is slightly higher than the values for typical indoor temperatures [4], [5], [7], [10], [14]. Because of specific environment, the values can be taken as an appropriate for the purpose of research of thermal conditions inside the vehicle cabin. 


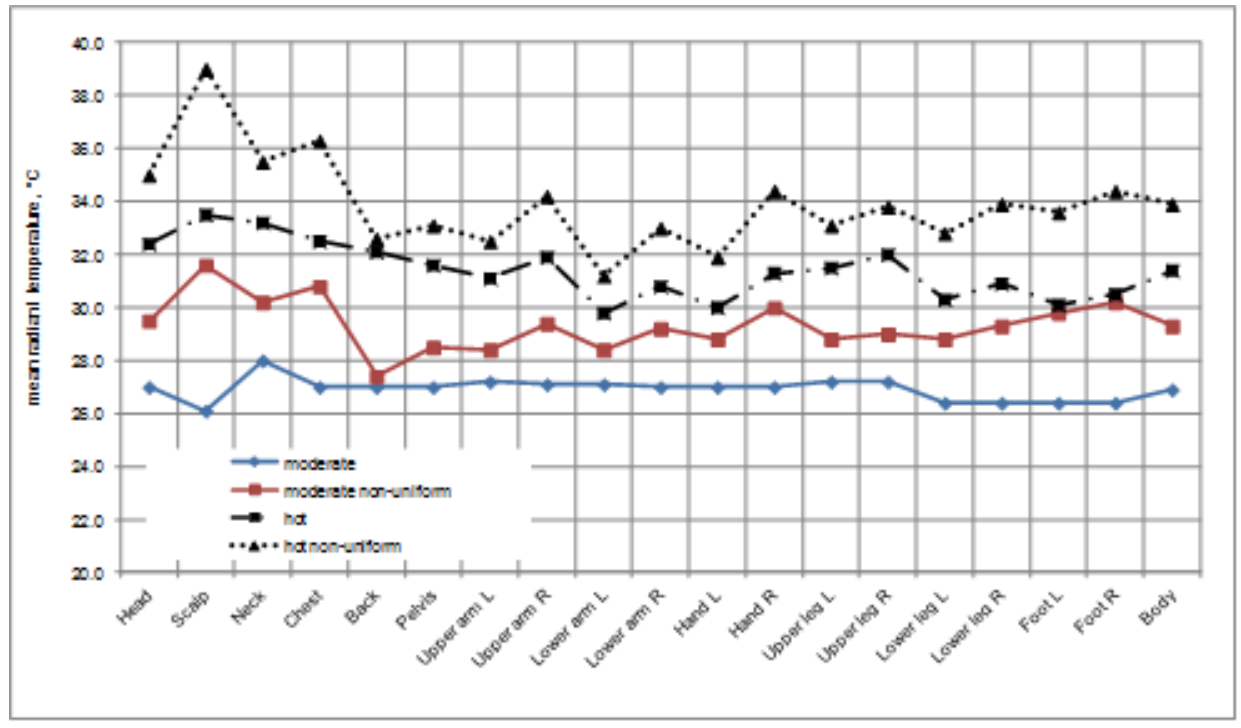

Figure 6 Mean radiant temperatures on individual segments of the driver's body

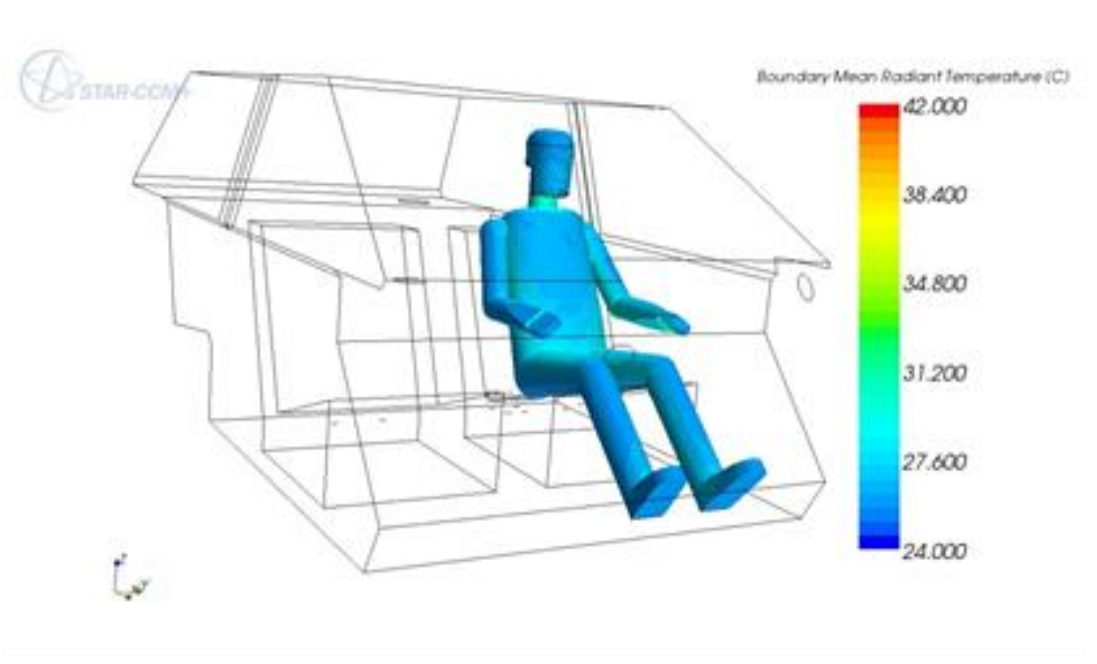

Figure 7 Visualisation of mean radiant temperature on the driver's body in moderate uniform conditions 


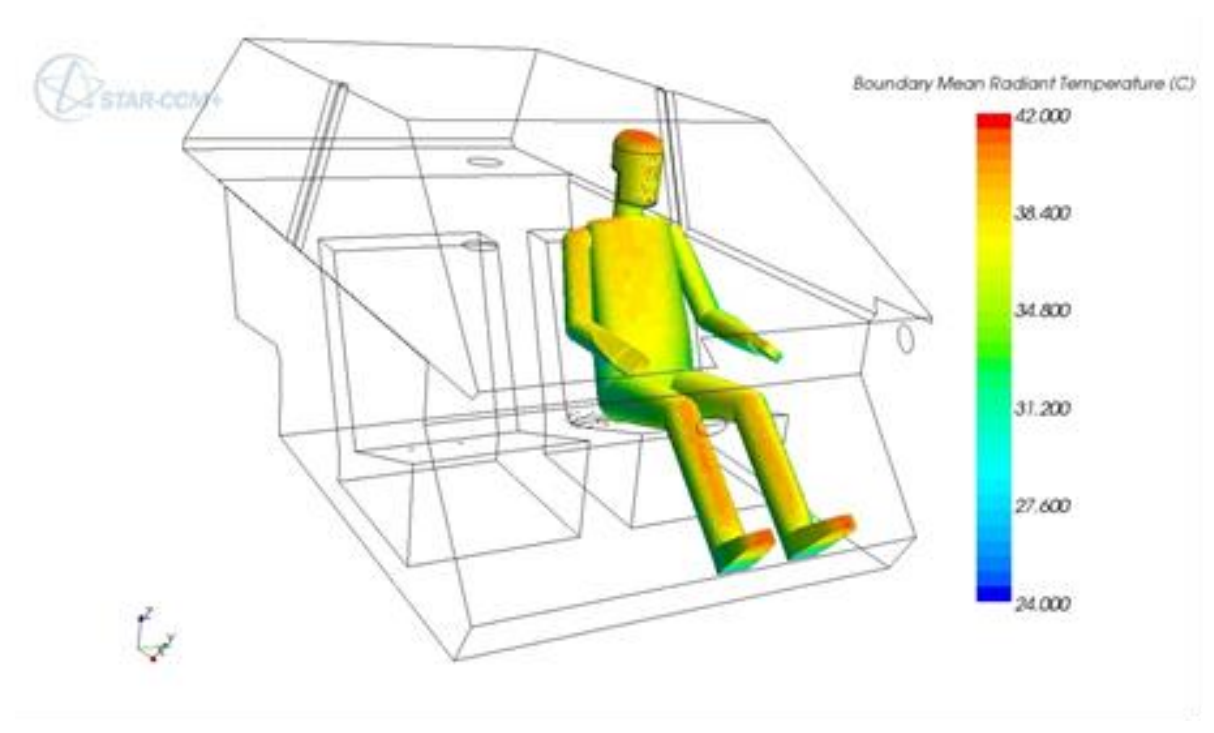

Figure 8 Visualisation of mean radiant temperature on the driver's body in hot nonuniform conditions

\section{CONCLUSIONS}

The influence of boundary conditions on thermal radiation between a driver and vehicle interior was analysed using the CFD software STAR-CCM+. The highest heat exchange occurs on segments that are directly exposed to the surrounding surfaces with high temperatures. Those body segments are head, arms and hands, i.e. the segments that are not covered by the clothing. The non-uniformity of the temperatures of the surrounding surfaces under chosen conditions obviously has less influence than the total heat transfer by thermal radiation.

In modelling of thermal radiation, correct data about surface emissivity and temperature are very important for accurate simulations. The values of linear radiative heat transfer coefficient obtained by the simulation post-processing are slightly higher than the values for typical indoor temperatures given in the literature, but because of specific environment, the values can be taken as an acceptable making the method suitable for further research of thermal conditions inside the vehicle cabin.

The advantages of the simulation method presented in this paper are the simplicity and independence from other modes of heat transfer. Although the gray thermal radiation model was used, the radiation can be modelled as spectrum-dependent.

For achieving accurate prediction of thermal radiation by simulations it is crucial to have comprehensive data about radiative properties of materials and boundary conditions. In any case, the numerical values obtained from the simulations should be considered for comparison purposes only, and validation of the numerical model must be done by physical experiment. 


\section{ACKNOWLEDGMENT}

This work was supported by Serbian Ministry of Education, Science and Technological Development under Grant TR35041 - "Investigation of the safety of the vehicle as part of cybernetic system: Driver-Vehicle-Environment". The authors wish to thank to Department for Energy and Process Engineering at the Faculty of Technical Sciences - University of Novi Sad, for enabling the use of the CFD software Star-CCM+.

\section{REFERENCES}

[1] Agošton, D.: "Analysis of microclimate conditions in motor vehicle cabin in transient conditions", master thesis, 2014, University of Novi Sad, Faculty of Technical Sciences.

[2] Bohm, M., Holmer, I., Nilsson, H., Noren, O.: "Thermal effects of glazing in driver's cabs", JTI-rapport, JTI - Institutet for jordbruks, 2002, Upsala, Sweden.

[3] Chen, K., Kaushik, S., Han, T., Ghosh, D., Wang, M.: "Thermal comfort prediction and validation in a realistic vehicle thermal environment", SAE International 2012-01645, 2012.

[4] De Dear, R., Arens, E., Hui, Z., Oguro, M.: "Convective and radiative heat transfer coefficients for individual human body segments", International Journal of Biometeorology Vol. 40, 1997, 141-156.

[5] Parsons, K.: "Human thermal environments: The effects of hot, moderate and cold environments on human health, comfort and performance", 2nd Edition, 2003, London, UK.

[6] Ružić, D.: "Influence of air-conditioning on thermal comfort in passenger vehicle", magister thesis, 2006, University of Novi Sad, Faculty of Technical Sciences.

[7] Ružić, D., Bikić, S.: "An approach to modelling a virtual thermal manikin", Thermal Science - International Scientific Journal Vol. 18, No. 4, 2014, Vinča, 1413-1423.

[8] Ružić, D., Časnji, F.: "Agricultural tractor cab characteristics relevant for microclimatic conditions", Journal of Applied Engineering Science Vol. 9, 2012, 323330.

[9] Ružić, D., Časnji, F.: "Thermal interaction between a human body and a vehicle cabin", Heat Transfer Phenomena and Applications, InTech, Rijeka, 2012, 295-318.

[10] Sorensen, D. N., Voigt, L. K.: "Modelling flow and heat transfer around a seated human body by computational fluid dynamics", Building and Environment Vol. 38, 2003, 753-762.

[11] ***, ASABE/ISO 14269-2: Tractors and self-propelled machines for agriculture and forestry - Operator enclosure environment - Part 2: Heating, ventilation and airconditioning test method and performance, 1997.

[12] ***, ASABE/ISO 14269-3: Tractors and self-propelled machines for agriculture and forestry - Operator enclosure environment - Part 3: Determination of effect of solar heating, 1997.

[13] ***, SRPS EN ISO 14505-2: Ergonomics of the thermal environment - Evaluation of the thermal environment in vehicles. Part 2: Determination of equivalent temperature, 2008.

[14] ***, Thermal comfort, Chapter 8, ASHRAE Fundamentals Handbook, 1997. 
Intentionally blank 